\title{
Research on Heuristic Curriculum Reformation of Mechanical Innovation Design Based on Virtual Design
}

\author{
Ping Xu \\ School of Electromechanical and Architectural \\ Engineering \\ Jianghan University \\ Wuhan City, China \\ Mytemp518@126.com
}

\author{
Jiangang Yi * \\ School of Electromechanical and Architectural \\ Engineering \\ Jianghan University \\ Wuhan City, China \\ yjg_wh@yeah.net
}

\begin{abstract}
In view of the existing problems in mechanical innovation design curriculum of high schools, the method of integrating the virtual design and heuristic education into the class is proposed in this paper. According to reforming the teaching and examining mode, the novel and innovative teaching method with modern education technology as means and cultivation of students' innovative ability and innovative consciousness as goals is presented. The examination shows the proposed method improves students' learning interest and learning effect, and has good application value in high schools.
\end{abstract}

Keywords-mechanical innovation design; curriculum reformation; virtual design; heuristic education

\section{INTRODUCTION}

Innovation is the soul of a nation's progress, as well as an inexhaustible motive force for national prosperity. However, compared with foreign universities, the understanding of basic knowledge and professional knowledge of our students is better, but their innovation ability is insufficient seriously. According to statistics, only in 1996, the students of MIT University put forward 400 inventions, which is the sum of the annual patent in China. In these years, millions of college students in China are graduated annually, but the creative talents among them emerge rarely. This indicates that China's higher education for the cultivation of creative talents is very weak [1].

At present, to cultivate students' innovation consciousness and improve students' innovation ability, many innovative curriculums have been opened in China's colleges and universities. Mechanical Creative Design (MCD) is the opened course in this context in recent years. It is a professional course in engineering colleges, aiming to cultivate students' innovative thinking and innovative ability. However, according to the study on the course, we find there are still some problems in the teaching process:

1) This course includes much knowledge involved in many other courses, such as mechanical principles, mechanical design, modern design method, hydraulic and pneumatic drive, numerical control technology, electromechanical transmission.
All these courses have their own experiments which are set independently. Therefore, in the course of MCD, the comprehensive and innovation experiments are lacked. Moreover, buying the relative teaching equipment costs lots of money yet may not be able to get good effect in this course.

2) The course covers knowledge of many courses and has large content capacity, but the teaching time is limited. Using traditional teaching method may make students feeling dull and losing interest in learning.

3) The purpose of MCD is to cultivate students' innovative ability, practical ability and comprehensive application ability, but the traditional classroom teaching technology can hardly reflect the students' innovation consciousness. This indicates in the curriculum assessment process, the traditional methods lack the test of comprehensive analysis and design ability of students, and may choke the development of students' creative thinking and innovation ability.

\section{HEURISTIC CURRICULUM REFORMATION BASED ON VIRTUAL DESIGN}

In view of the above question, we develop the heuristic teaching method based on virtual design according to the curriculum inherent laws of MCD. The essence of the method is as follows. First, through the vivid 3D virtual animation designed by teacher, students can master the basic concepts of knowledge points. Second, with the demonstration of specific virtual experiments constructed by virtual design software, students can associate the text knowledge with virtual mechanism. Finally, students are encouraged to use virtual design software to carry out the relevant experiments. In this way, students are inspired to link text knowledge and innovative thinking. The teaching result shows it is effective of raising student's independent exploration ability, experimental operation ability and scientific research interest.

In the teaching class, we choose SolidWorks as the virtual design software. SolidWorks is a 3D CAD system software based on Windows, which provides 2D and 3D engineering drawing including all the required mechanical design, 
verification, data management and communication tools, and has the characteristics of easy to learn and use. We used the SolidWorks 2008 to construct the demonstration experiments, which help the students to thinking in images, and improve students' ability of space imagination and the expression ability. After the virtual experiments, students propose the ideas and methods to solve the professional knowledge problem of each unit in MCD by their own.

Figure I shows a student's virtual innovation design after learning the "principle of mechanism combination" section of MCD course. Through the observation of the daily life of clothes hanger, the student found traditional clothes hanger has the defects of single function, inconvenience installation, and lack of drying indoor and outdoor. Therefore, through the demonstration and inspiration of the virtual design of the fishing rod mechanism and the link mechanism, the student independently designed the innovative clothes hanger by using the parallelogram mechanism and the locking mechanism. Through the rod telescopic, folding, assembly and locking, the novel clothes hanger has a variety of functions such as clothes hanger, hanger indoor and outdoor, clothes fork, and wall brush. The invention has the merits of simple whole structure, small space occupation, convenient assembly and disassembly, beautiful appearance, convenient movement, and low price. The design has been made into products, and has been declared a patent. Based on the heuristic teaching method of virtual design of MCD, the bad side of narrative introduction and mathematical derivations, and the lack of innovative design of experiments in traditional teaching are changed. With the heuristic teaching method of virtual design, the students' enthusiasm for innovation is inspired and their innovation thinking is improved.

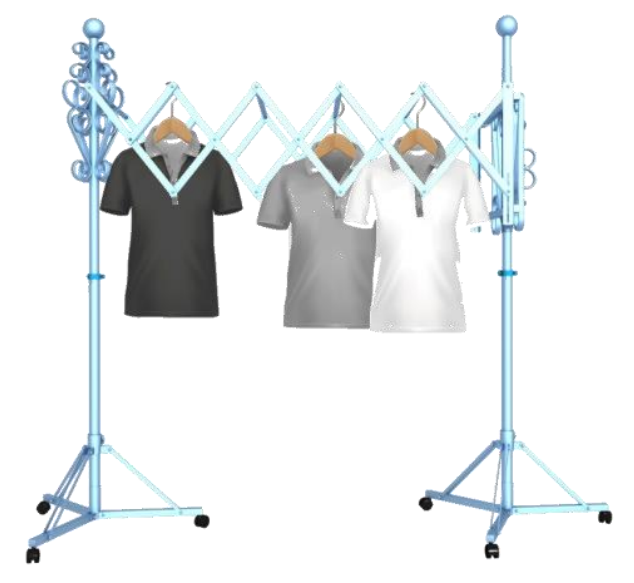

FIGURE I. THE INNOVATIVE CLOTHES HANGER

\section{HEURISTIC EVALUATION REFORMATION BASED ON VIRTUAL DESIGN}

Innovative design ability is reflected in the aspects of theoretical analysis, data use, and comprehensive judgment. The traditional closed examination is difficult to reflect on the innovation design ability examination of students. At the same time, it does not contribute to the comprehensive analysis of students and the ability to solve practical problems. What's more, this form of examination and the test contents also feedback to the teaching process, restricting the selection and expansion of the teaching contents. Therefore, we adopt a new evaluation of MCD course. That is, the design goal is given by teacher, which includes a brief description to design a creative mechanism or mechanical systems function. However, the specific objects and methods are chose by students freely. The assessment scores results from the technical index of virtual design works (including technical system performance, life, reliability, security, manufacturing process, use and maintenance of advanced technology, etc.), economic indicators (including project cost, investment, profits, recovery period), social indicators (including social influence, scheme of energy saving and environmental protection, sustainable development).

For example: an appraisal subject about the bike used in our daily life is put forward. Students are asked to observe the structure of the bicycle, to find the problem and put forward the reform plan. Some students present a problem that after a period of riding time, the bicycle chain is easy loosed, which affect the use of bicycle. With the guidance of students' innovative thinking, the chain transmission mechanism for bicycle is improved, as shown in Figure II. By adding a chain wheel and a connecting rod mechanism, the chain can not only be pressed, but the pedal power can be transmitted to a small fan at the top of head cover, which can provide cool air in hot days. On the base of it, some other students present the idea of adding a convenient folding cover on the bike so as to provide the shelter and shade effect.

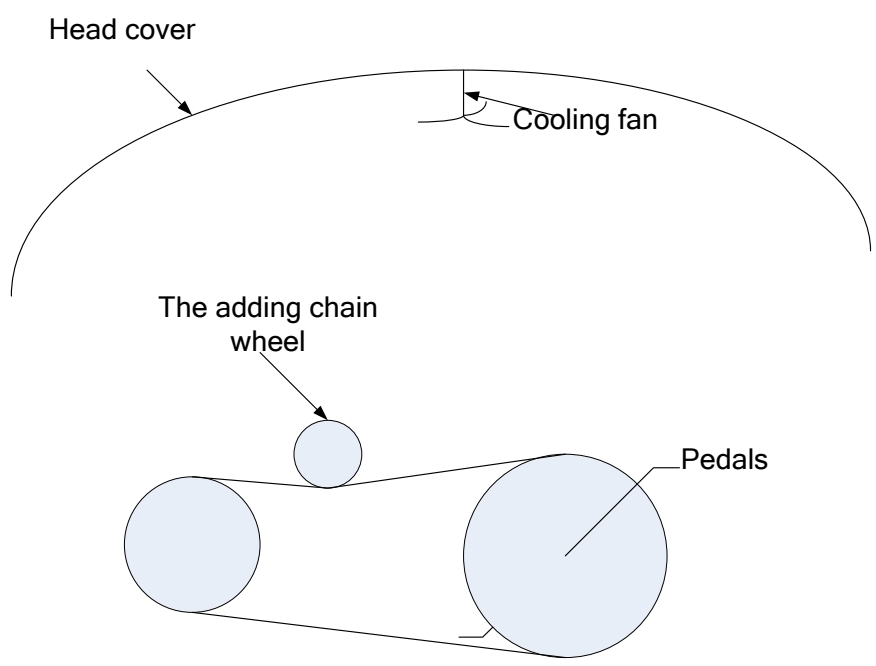

FIGURE II. THE IMPROVED BICYCLE

By using this heuristic evaluation method of virtual design, we change the traditional "recite type" examination mode to "research type" assessment model, motivating students' interest in learning, stimulating students' desire for innovation, as well as improving students' learning effect. As a result, students can have a better grasp of the knowledge of the MCD course in a relatively short period of time, and their innovation ability, practice ability comprehensive application of knowledge ability can be improved effectively. 


\section{THE EFFECT OF IMPLEMENTATION}

The heuristic curriculum reformation of MCD based on virtual design has been implemented in our school. The work is conducted in a natural class of mechanical engineering students, and supported by the school administration office. From the students' exam scores of the course before and after the reform, the reform result is satisfactory. After the implementation of the new teaching method and the new evaluation method, the students' average score is 17 points higher, and the students' number not passing the exam is dropped to 0 . The excellent rate increased by about 11 percentage points, and the good rate increased by about 19 percentage points, see Table I.

TABLE I. ANALYSIS OF CURRICULUM BEFORE AND AFTER THE REFORMATION

\begin{tabular}{|c|c|c|c|c|c|c|}
\hline & $\begin{array}{c}\text { Average } \\
\text { score }\end{array}$ & Excellent & Good & Normal & Pass & Fail \\
\hline Before & 67 & $5.2 \%$ & $20.9 \%$ & $29.8 \%$ & $\begin{array}{c}40.1 \\
\%\end{array}$ & $4 \%$ \\
\hline After & 84 & $16.7 \%$ & $39.2 \%$ & $28.3 \%$ & $\begin{array}{c}15.8 \\
\%\end{array}$ & $0 \%$ \\
\hline
\end{tabular}

Through the curriculum reformation, our students generally reflect they have more specific understanding of the abstract concepts, and more profound master of the knowledge points. The reformation promotes student independent learning ability and independent innovation ability, and improves students' creative thinking and teaching quality. Moreover, the curriculum reformation closely associate with the subject of Ministry of education of the National College of mechanical innovation design competition, providing a better theoretical guidance and support platform for students. At the end of the 2012 national undergraduate mechanical creative design contest, our students won 2 national second prizes, and 4 Hubei Province first prizes.

\section{CONCLUSIONS}

Aiming at the existing teaching problems of MCD course, we propose the curriculum reformation to develop students' creative thinking and enhance their innovation ability, which focus on the goal of training the professional talents who can adapt to the needs of modernization of the twenty-first Century, as well as has a strong sense of competition, innovation spirit and practical ability. The innovative talent education target is achieved from the two aspects of the reform of teaching method and curriculum assessment methods, and the heuristic method based on virtual design is used to stimulate students' enthusiasm and creativity. The curriculum reformation has laid the foundation for the construction of machinery innovation design course, exploring the combination of classroom teaching and experiment teaching content, mode, and method. The results show the measures of MCD curriculum reformation is practical and effective.

\section{ACKNOWLEDGMENT}

This work is partially supported by the Research Project of School of Electromechanical and Architectural Engineering, Jianghan University (granted number: JD005). The authors also gratefully acknowledge the helpful comments and suggestions of the reviewers, which have improved the presentation.

\section{REFERENCES}

[1] Li Zhujun, Chen Hui, The curriculum reform and practice of mechanical innovation design with CDIO in higher vocational education, Proceedings of 2012 7th International Conference on Computer Science and Education, pp. 1430-1432, 2012.

[2] Zhang Ximiao, Zhou, Yuexi, Educational reform of importing chinese traditional color culture into the design education after cultural innovation, Applied Mechanics and Materials, vol. 201-202, pp. 10171020, 2012.

[3] Jiang Sun, Qi Xiao, Manufacturing and innovation ability education of university students majored in mechanical engineering, Applied Mechanics and Materials, vol. 229-231, pp. 2779-2783, 2012.

[4] B.Williams Christopher, Gero John, Lee Yoon, Exploring the effect of design education on the design cognition of Mechanical Engineering students, Proceedings of the ASME Design Engineering Technical Conference, vol. 7, pp. 607-614, 2011

[5] Seidel Rainer, Haemmerle Linda, Chambers Chris, A multidisciplinary design education approach for supporting engineering product innovation, ASEE Annual Conference and Exposition, 2007

[6] Peruzzini Margherita, Mengoni Maura, Germani Michele, Evaluating the impact of virtual reality on mechanical design education, Proceedings of the ASME/AFM World Conference on Innovative Virtual Reality 2009, pp. 107-115, 2009 